\title{
Identifying Crisis Threats: A Partial Synthesis of the Literature on Crisis Threat Assessment with Relevance to Public Administrations
}

\author{
Christian Kalbassi \\ Swiss Graduate Institute of Public Administration, Faculty of Law, Criminal Justice and Public Administration \\ University of Lausanne, CH-1015, Lausanne, Switzerland \\ E-mail: christian.kalbassi@unil.ch
}

Received 30 March 2016

Accepted 15 June 2016

\begin{abstract}
The crisis management literature offers a host of theoretical treatises that are relevant to crisis threat assessment in public administrations; however, these insights remain non-cumulative, non-consolidated, and unstructured in a field of individual contributions. Using existing literature regarding crisis definitions, crisis classifications, and crisis threat assessment tools, this exploratory paper identifies crucial analytical approaches to crisis threat assessment with relevance to public administrations. A critical evaluation of the specific research reveals gaps in the theoretical knowledge base and identifies three conceptual requirements for promoting a profound theorization of the field: the provision of relevant crisis threat variables, the specification of these variables, and the consolidation of the existing crisis threat assessment literature.
\end{abstract}

Keywords: Crisis threat identification, crisis threat assessment, crisis classification, analytical methods, analytical frameworks, public administration.

\section{Introduction}

With recent modernization processes (Boin and 't Hart, 2003) and the emergence of new global risks (Beck, 2007), crises have become more complex. The new millennium brought with it 'a series of new crisis challenges due to climate change and environmental issues, increasingly risk-prone vital networks, massive terrorist threats, huge increases in the cost of disasters due to global coupling and just-in-time production methods, global civil unrest, and financial and economic meltdowns' (Topper and Lagadec, 2013: 5). To address these new circumstances, crisis management scholars require analytical methods and frameworks that are better adapted for crisis threats (Boin and McConnell, 2007; Doktor, 2007; Enander, Lajksjö and Tedfeldt, 2010; Gundel, 2005; Kouzmin, 2008; Lalonde, 2007; Quarantelli, 2001; Robert and Lajtha, 2002; Rosenthal, Boin and Comfort, 2001; Roux-Dufort, 2007; Topper and Lagadec, 2013). However, the design of appropriate analytical methods and frameworks - which are hereinafter summed up as "analytical aids" - is challenging. A profound conviction led the field to the basic assumption that the essence of a crisis is a "wild and maverick reality, impossible to understand and grasp within frameworks shaped, built and stamped to contain stable and repeated phenomena' (Topper and Lagadec, 2013: 8). Consequently, the field suffers from methodological monolithism, caused by a strong focus on case studies and an underestimation of theorization attempts (Roux-Dufort, 2007). Indeed, the assumption of non-generalizability of previous results may prevent or complicate the introduction of new and sustainable analytical aids. This raises the issue of what cross-case relevant analytical aids for identifying crisis threats with relevance to public administrations have already been implemented and what key crisis threat variables they refer to. 
In order to address this concern, this study provides an in-depth review and analysis of the literature on crisis threat assessment with relevance to public administrations, using three angles: crisis definitions, classifications, and assessment tools. The objective is to offer a foundation to develop new analytical aids in the field. The following research questions will be answered: a) What conceptual requirements would promote a profound theorization of the field of crisis threat assessment with relevance to public administrations? and b) What key crisis threat variables are relevant to the specific field?

To answer these research questions, a thematic literature review has been performed. The purpose of such a review can be, among others, to discover important variables relevant to a topic and to distinguish what has been done from what needs to be done (cf. Hart, 1998). Over 200 relevant books and journal articles were studied, and 87 crisis threat variables with relevance to public administrations were identified. After carefully examining each item, they were reduced to 22 distinct variables. Table 2 lists the identified variables.

Hereinafter, "crisis threats" refer to anything that would contribute to the tampering, destruction, or interruption of any service or item of value in a governmental jurisdiction (Bayne, 2002). "Crisis threat variables" are presented as factors that determine whether or not a situation develops into a certain type or intensity of a crisis.

\section{Literature Review}

Regardless of whether crises evolve abruptly or cumulatively (Hwang and Lichtenthal, 2000), the phases of crisis management can roughly be divided into 'horizon scanning', 'early warning/preparation', 'containment', 'recovery/disaster', and 'evaluation'. In the first two phases, the crisis has not yet occurred and therefore preventive actions are the main concern. In phase three, the crisis hits an organization or a system and crisis mitigation measures are required, whereas in the fourth and fifth, a conclusion involving a recovery or catastrophic escalation of the situation gradually emerges (Claeys and Cauberghe, 2014; Mitroff, 1988; Sikich, 1995; Töpfer, 1999).

Crisis threat assessment is the process through which a manager or leader makes sense of a crisis situation in order to develop an effective crisis plan (Yin and Jing, 2014). It starts in phase three of crisis management when, for example, a manager or leader realizes that a crisis is arising. When focusing on crisis threat assessment, the probabilities of crisis occurrence and prevention are not the main topics of interest, as would be the case in risk assessment (Habegger, 2010). In this article, crisis threat assessment is not understood as part of risk assessment or the identification of possible threats before they occur, but rather a process that supports managers or leaders with the identification of more or less apparent threats that emanate from the crisis. At this point, the crisis is already evolving, and crisis threat patterns must be described for the derivation of appropriate crisis-response strategies. Situation awareness processes - in other words, knowing what is going on around you (Crichton, Lauche and Flin, 2005; Endsley and Garland, 2000) become the focal point. Situation awareness has been identified as a crucial component of the decisionmaking process (Canon-Bowers and Bell, 1997); hence, making an accurate crisis threat assessment is the most critical aspect of a crisis response (Shapiro and Koocher, 1996). In particular, in combination with the quickly evolving nature of a crisis, inaccurate situational assessments can lead to a multidimensional crisis and an insidious threat pattern. Therefore, identification of the key variables shaping the crisis is an important prerequisite for developing an effective crisis management plan (Yin and Jing, 2014).

Previous studies distinguish between the 'objective' and 'subjective' dimension of crisis assessment: The objective view describes crisis threats as existing in "real" form in the world. This means that the threats can be assessed by measureable variables with respect to the magnitude and severity of the consequences (Gephart, Van Maanen and Oberlechner, 2009). The subjective view addresses the crisis management process, including the individual judgments and perceptions of managers, and therefore represents the perspective of how people subjectively perceive crisis threats to themselves, groups, or organizations (Boin, 2005; Weick, 1993; Yin and Jing, 2014). This study addresses the objective view. Processes associated with the crisis mitigation phase that result from managerial failures during crisis management (e.g., Sheaffer, Richardson and Rosenblatt, 1998) and errors linked to media 
communication (Pasquier and Fivat, 2012) are thus not the primary focus of this paper.

There are at least three distinguishable approaches in the crisis management literature that are germane to the objective view of crisis threat assessment: Crisis definitions determine which potential events or circumstances can be examined, crisis classifications discuss patterns of crises in terms of pertinent crisis attributes, and the more practice-oriented crisis threat assessment tools provide crisis threat assessment frameworks to managers and leaders (see overview of the three approaches in Table 1).

\subsection{Crisis definitions}

Crisis definitions describe the primary underlying characteristics of crises. They examine crises from the viewpoint of the characteristics that constitute a crisis situation (Hwang and Lichtenthal, 2000) to distinguish them from other situations. Despite diverse crisis definitions, most crisis researchers agree on the major characteristics of crises: potential threats, triggers, some form of incubation, uncertainty about the resolution of a crisis and its after-effects, time pressures, and potentially harmful impacts on individuals, organizations, or society as a whole (Lalonde, 2011). Summarized in one sentence, a crisis can be defined as 'a serious threat to the basic structures or the fundamental values and norms of a social system, which - under time pressure and highly uncertain circumstances - necessitates making critical decisions' (Rosenthal, Charles and 't Hart, 1989: 10). ${ }^{1}$

The above definition applies to all types of disruption, including eco-threats, information technology (IT) crashes, economic adversity, intrastate conflicts, prison riots, regional wars, exploding factories, and natural disasters (Dayton, 2004). These disruptions can have immediate and measurable effects such as pollution, fire, and the cost of intervention, as well as indirect effects such as changes in laws and damage to reputations (Jaques, Gatot and Wallemacq, 2007). The definition suggests an abrupt and severe disruption of the routine processes and institutional structures of a social system (Boin, 2005), which can be

\footnotetext{
${ }^{1}$ For a more detailed description of the criteria "threat", "uncertainty" and "urgency", see Stern, E., 2014. From Warning to Sense-making: Understanding, Identifying and Responding to Strategic Crises, OECD 2014.
}

defined as a general precondition for a crisis. However, these disruptions are not easy to identify in practice, as they are often rooted in a variety of human, social, technical, economic, legal, and ethical dimensions, which in turn complicates the unified definition of a crisis (Jaques, Gatot and Wallemacq, 2007). Thus, the concept of crisis in the crisis management literature remains vague (Roux-Dufort, 2007; Roux-Dufort and Lalonde, 2013; Topper and Lagadec, 2013); this vagueness can be explained by the fact that the identification and acceptance of a crisis is largely dependent on the perceptions of the relevant actors (Boin, 2005; Svedin, 2009; 't Hart and Boin, 2001).

Consequently, a crisis definition cannot simply rely upon clearly specifiable indicators. This is the primary disadvantage of the concept of crisis: Its main characteristics are, to a great extent, open to interpretation. Major problems arise, for example, from the question of how "time pressure" should be measured: Many crises such as the 2008 financial market crisis allow for a comparatively long response time in comparison to a crisis caused by a flood or a technological disaster. The decision of the Swiss Federal Council to bailout the Union Bank of Switzerland (UBS) with 66 billion Swiss francs was made ten months after the serious liquidity problems were detected at the bank, nine months after the installation of a prestigious crisis management team with representatives at the highest level of state, and one month after Lehman Brothers declared bankruptcy. In all three cases (flooding, technological disaster, and financial market crisis), time pressure is high, but the period of action cannot explicitly be reduced to a specific time scale.

It can be said that there is a lack of consensus as to what is a crisis (Antonacopoulou and Sheaffer, 2013). However, when a situation roughly satisfies the definition of a crisis (e.g., threat, time pressure, uncertainty, etc.), it is suitable for crisis threat assessment. Whilst the suitability of a situation for assessment can be established by diagnostic aids (Stern, 2009), the specific influence of crucial crisis threat variables must be based on other theoretical foundations. In order to obtain a more differentiated view of these variables, particular attention must be paid to crisis classification. 


\subsection{Crisis classification}

Crisis classification is a method for explaining crisis phenomena and the interdependence of specific crisis threat variables. Gundel (2005: 106) emphasizes the importance of typologies for practical implications and improved understanding of crisis phenomena: 'If one wants to know how different types of crises develop, what kinds of problems surround them and, most important, how they can be handled, (...) a classification would surely be helpful by identifying common traits of different crises.' Consequently, crisis management scholars have approached the topic via primary causes or primary traits (e.g., natural, technological, social, economic, political), one specific attribute (i.e., national vs. international, episodic vs. continuous, corporate vs. public, and normal vs. abnormal), segmentation (i.e., internal, external, technical, and organizational), time scaling (i.e., before, during, after), topical categories (e.g., product defects, international crises), and crisis components (cf. Gundel, 2005; Topper and Lagadec, 2013).

Early forms of classification had a strong emphasis on the causes and triggers of crises. The distinction between 'natural' and 'man-made' disasters dominated the early years until the end of the 1980s (Rosenthal and Kouzmin, 1993). At that point, Mitroff, Pauchant and Shrivastava (1988) came up with a more complex classification along internal-external and technicalsocial axes and suggested that organizations should consider forming dual crisis portfolios for preventive actions and crisis clusters. If organizations introduced such portfolios, it was argued, they could protect themselves with minimal coverage across the crisis cause clusters 'external/internal threats', 'breaks', 'psychopathic threats', and 'external actions/threats'. Rosenthal and Kouzmin (1993) took up this common distinction form and extended it by creating subgroups of natural and man-made disasters by introducing the subclusters of mine disasters, oil spills, air disasters, crowd disasters, nuclear crises, terrorism, and chemical explosions.

Hwang and Lichtenthal (2000) broke with the established tradition, arguing for a classification based on the ways in which a crisis develops instead of focussing on the causes. Based on the theory of punctuated equilibria in biology, they present a distinction between abrupt and cumulative crises by focusing on dimensions such as 'build up speed', 'predictability', 'specificity', 'recognition', ‘trigger point', 'probability of occurrence', and 'misalignment with environment'. Abrupt crises are relatively quick to emerge, hard to predict, clearly recognizable, triggered by a specific event, time-constant, and more aligned with the environment than cumulative crises, which are more likely to evolve gradually and are highly predictable, difficult to recognize, triggered by a threshold-limit, time-increasing, and in many aspects misaligned with the environment. With regards to the Y2K-related IT problems known as the 'Millennium bug', Quarantelli (2001) asserted that former typologies were outdated because they ignored relevant attributes such as social consensus, political will, and the influence of mass media. He noted that the Y2K problem was comparably easy to solve because of the crisis-specific social consensus on what could be done, who would do it, and the resources that had to be provided. Inspired by the attacks on the World Trade Centre in 2001, Mitroff and Alpaslan (2003) emphasized the need to distinguish 'normal crises' from 'abnormal crises'. Whereas normal accidents involve known types of personnel, as well as physical and economic crises, abnormal accidents represent criminal crises such as acts of terrorism, information crises, and reputation crises. Gundel (2005) opted for a more methodological approach, claiming that the older typologies failed to meet mandatory requirements for a typology (i.e., encompassing all kinds of crises, considering related prevention and response measures for each class, and a manageable and exclusive number of subsets). With respect to these conditions, Gundel identified the proactive criteria 'predictability' and the reactive 'influence' that determined four crisis clusters: conventional, unexpected, intractable, and fundamental crises.

In fact, following Gundel's call for more sufficient typologies, a sudden historical caesura can be noted in the development of classifications with relevance to public administrations. Recent publications largely dispense with crisis classification, and scholars have not replaced or extended it with more appropriate approaches. It seems that the expanding complexity of crises has made it increasingly difficult to introduce new crisis classifications. An almost confusing wealth of contributions to the understanding of individual 
phenomena of crises has become the focus of the recent literature, which can be divided into four dimensions that are relevant to crisis threat assessment in public administrations: crisis threats to a system/society, the quality of information for crisis threat assessment, political-administrative challenges, and the assertiveness of a crisis management team. ${ }^{2}$

The first dimension describes threats emanating directly from the crisis, such as the novelty of a crisis (Howitt and Leonard, 2009), the human, environmental, economic and societal extent of crisis damage (Hohl, Brem and Balmer, 2013), the reversibility of the damage (German Advisory Council on Global Change, 1998; La Porte, 2007), the latency of the effects of the crisis (German Advisory Council on Global Change, 1998; La Porte, 2007), the alignment of crisis effects with the environment (Hwang and Lichtenthal, 2000), the spatial impact (German Advisory Council on Global Change, 1998; International Risk Governance Council, 2008), and the mobilization potential of a crisis (Fink, 2000; German Advisory Council on Global Change, 1998). The second dimension outlines the quality of information available in the particular crisis, such as the completeness of knowledge about the causes and evolution of the crisis (Ansell, Boin and Keller, 2010; La Porte, 2007), the uncertainty over solutions (Ansell et al. 2010), the access to information relevant for diagnosis and resolution, the consensus on the severity of the crisis among relevant actors, and the consensus on the utility/credibility of the available information ( $\mathrm{La}$ Porte, 2007). The third dimension determines the integration of other political-administrative capabilities in crisis mitigation. Ansell et al. (2010) assert that crises have become increasingly 'transboundary' in nature in recent years, challenging political-administrative capabilities in terms of the number of governments involved, the extent of policy areas affected, and the past and future actors involved. A crisis is more difficult to respond to when it scores high on these three dimensions. The fourth and final dimension describes the assertiveness of the crisis manager or the crisis manager's organization in relation to the emerging crisis. Dimensions include whether the crisis management team shares responsibility for the crisis (Brown and Ki, 2013; Coombs, 2007; Fink, 2000;

\footnotetext{
${ }^{2}$ For a summary overview of the four dimensions, see Table 2.
}

McAuley, Duncan and Russell, 1992), whether the crisis interferes with the normal operations or daily business of the crisis manager's organization (Fink, 2000), and whether there is the potential for contradictory strategies or meaning-making processes in the area affected (Ansell, Boin and Keller, 2010; Klinke and Renn, 2001).

In summary, crisis classifications provide many insights into crisis phenomena and are significantly more precise in describing crucial crisis threat variables than crisis definitions. The many individual contributions lead, in aggregate, to a differentiated view of the influence of specific crisis threat variables. However, non-cumulative and non-consolidated contributions make it difficult to deal with the variety of potentially relevant variables. In order to minimize this problem and to achieve a certain degree of applicability to crisis threat assessors, some crisis management scholars have developed crisis threat assessment tools, as discussed in the next section.

\subsection{Crisis threat assessment tools}

Crisis threat assessment tools deliver a framework that is oriented towards practical responses and that should help crisis assessors identify potential crisis threats. Turning the mountains of raw data (e.g., reports, rumours, and pictures) into a coherent picture of the situation is indeed a major challenge in itself (Ansell, Boin and Keller, 2010). However, only a few noncumulative contributions that are relevant to public administrations can be identified in the existing literature.

Fink's (2000) approach was intended to support managers and leaders with a crisis threat assessment tool that facilitated the entire process of crisis threat assessment. Five variables (i.e., 'intensity', 'media or government scrutiny', 'interference with normal operations of business', 'threat to public image', and 'impact on a company's bottom line') are scored on a scale from 1 to 10 , which reveals how damaging a crisis may be if there is no crisis intervention; these figures can then be plotted on a crisis barometer that combines the axes 'probability' and 'crisis impact value'. Lewis' (2006) 'Human Impact Assessment Tool' enables a planner to consider the social and emotional impacts of a crisis on the personnel in a crisis-affected organization. The factors 'locus/area of impact', 
'preparation/capacity to manage the incident', 'duration of the event', 'impact on operations', 'damage to premises', 'damage to reputation', 'injury and death to personnel', 'external damage and injury', 'impairment of personal property', 'impact on and damage to social structure', and 'concurrent stressors' focus on more than the estimated stress level of the workforce. This tool requires rating each factor on a scale from 1 to 10 and defining an overall crisis-tolerance threshold. La Porte (2007) focused on the properties of crises that have strong implications for organizational design, specifically when political and agency leaders consider enhancing the crisis management capacity of their institutions. The conditions 'consensus on seriousness of the crisis', 'overall magnitude', 'speed of crisis unfolding', 'propagation of effects', 'perceived duration of effects', 'knowledge of causes and consequences', 'mix of information for diagnosis/remedy', and 'consensus on utility/credibility of information' may present themselves in a variety of combinations, thereby multiplying the management challenges that can confront the institutions charged with responding to crises. In general, the higher the cumulative score for the anticipated crisis effects and the lower the confidence in the available information and causal knowledge about the particular crisis, the more likely it is that institutional disarray and systemic collapse will result.

Because the authors of these crisis assessment tools did not derive their variables in a retraceable manner from crisis management theory, it is difficult to determine the train of thought that led to the identification and selection of the variables. Due to their intent to establish order out of chaos, the authors all chose heuristic methods to conceptualize their theoretical constructs. In summary, crisis threat assessment tools identify key crisis threat variables and operationalize them through scales and threshold values; however, the lack of a theoretical foundation, the relatively low number of contributions to the field, and the differing fields of application (e.g., human impact, organizational crises) make it difficult to use them as analytical aid in their current state.

Table 1 gives an overview of the three presented approaches: crisis definitions, crisis classifications, and crisis threat assessment tools.

\section{Synthesis: Three Conceptual Requirements for Promoting a Fundamental Theorization of the Field}

In light of the research literature presented above, it is evident that the crisis management literature provides a host of contributions that are relevant to threat assessment by public administrations. However, these insights are scattered, vague in variable definition, and only applicable to particular fields in crisis management. This indicates a lack of theorization in the field of crisis threat assessment. In order to discuss this statement in more detail, three conceptual requirements for promoting a fundamental theorization of the field of crisis threat assessment with relevance to public administrations will be discussed: the provision of relevant crisis threat variables, the specification of these variables, and the consolidation of the existing literature on crisis threat assessment.

\subsection{Provision of relevant crisis threat variables}

Today, crises can result from complex interlinked circumstances; thus, the causes are frequently not only unique but also difficult to identify, even in retrospect. In a crisis, it is often unclear which crisis attributes are dependent (i.e., influenced factors) and which are independent (i.e., influencing factors). One can even expect that factors will change direction several times during a crisis. Intense media coverage, for example, can result from a lack of crisis communication or from high sensitivity in the population, politicians, or media representatives. Therefore, it is not the crisis causes that should be the focus of crisis threat assessment, but rather the circumstances in which a crisis is embedded. Every crisis has a social impact that transforms any type of crisis cause into a unique threat pattern for organizations or systems. Earthquakes, floods, technological disasters, mass demonstrations, and cyber-attacks only cause crises in relation to sociallysignificant effects. The primary challenge is therefore to identify the variety of relevant crisis threat variables that determine the potential for a situation to develop into a crisis.

In other words, the field of crisis management must shift its attention on crisis threat variables that explain the potential impact (e.g., the specific damage potential 
Table 1. Overview of the three approaches: crisis definitions, classifications, and threat assessment tools.

\begin{tabular}{|c|c|c|c|}
\hline & Crisis definitions & Crisis classifications & $\begin{array}{l}\text { Crisis threat assessment } \\
\text { tools }\end{array}$ \\
\hline Objective & $\begin{array}{l}\text { Identification of } \\
\text { commonalities among all } \\
\text { crises }\end{array}$ & $\begin{array}{l}\text { Categorization of crises through } \\
\text { specific attributes }\end{array}$ & $\begin{array}{l}\text { Assessment support for } \\
\text { managers and leaders in } \\
\text { crisis situations }\end{array}$ \\
\hline Structural approach & $\begin{array}{l}\text { Distinction of crises from } \\
\text { other events or conditions } \\
\text { using main crisis } \\
\text { characteristics }\end{array}$ & $\begin{array}{l}\text { Determination of crisis clusters } \\
\text { through the influence of } \\
\text { specific crisis attributes }\end{array}$ & $\begin{array}{l}\text { Provision of relevant crisis } \\
\text { variables for crisis threat } \\
\text { assessment }\end{array}$ \\
\hline $\begin{array}{l}\text { Determination of key } \\
\text { variables for crisis threat } \\
\text { assessment }\end{array}$ & $\begin{array}{l}\text { Low, due to highly } \\
\text { interpretable variables }\end{array}$ & $\begin{array}{l}\text { Low, due to scattered } \\
\text { discussion of crisis phenomena }\end{array}$ & $\begin{array}{l}\text { High, due to the } \\
\text { comprehensive presentation } \\
\text { of relevant variables }\end{array}$ \\
\hline $\begin{array}{l}\text { Abundance of variables for } \\
\text { crisis threat assessment }\end{array}$ & $\begin{array}{l}\text { Low, due to the limited } \\
\text { number of variables discussed }\end{array}$ & $\begin{array}{l}\text { High, due to the discussion of a } \\
\text { wide range of crisis threat } \\
\text { variables }\end{array}$ & $\begin{array}{l}\text { Low, due to the limited } \\
\text { number of variables } \\
\text { discussed }\end{array}$ \\
\hline Data collection method & Heuristic & $\begin{array}{l}\text { Relatively heuristic but } \\
\text { selectively validated by } \\
\text { methodological standards such } \\
\text { as surveys }\end{array}$ & Heuristic \\
\hline $\begin{array}{l}\text { Operationalization of } \\
\text { variables }\end{array}$ & None & None & $\begin{array}{l}\text { Yes, but no detailed } \\
\text { explanation about the } \\
\text { scaling method and scaling } \\
\text { levels }\end{array}$ \\
\hline $\begin{array}{l}\text { Test by confirmatory } \\
\text { methods }\end{array}$ & None & None & None \\
\hline $\begin{array}{l}\text { Inclusion of new } \\
\text { theoretical insights }\end{array}$ & $\begin{array}{l}\text { No significant modification } \\
\text { for more than } 10 \text { years }\end{array}$ & $\begin{array}{l}\text { No significant modification } \\
\text { since Gundel's classification in } \\
2005\end{array}$ & No theoretical debate at all \\
\hline
\end{tabular}

and the management challenges that crises pose to organizations and systems) so as to move away from the causal perspective. Recent crises have become increasingly transboundary and interconnected (Boin and Lagadec, 2000) and intensively scrutinized by the media ('t Hart, Heyse and Boin, 2001), and thus crisis causes become extremely difficult to identify. The increase in dynamic interrelations in today's world can be depicted by the significant historical increase in crisis damage costs: The average insured global cost of man-made disasters and natural disasters was about 6 billion USD/year in the 1970s and 1980s, whereas it amounted to about 60 billion USD in 2014 (Swiss Re, 2015). Technological and residential development, economic interdependence, and population growth all make society more vulnerable to crises. In previous decades, for example, a natural disaster would potentially impact a few farmhouses, whereas today in the same location, a small city that has significant economic power and a high level of interconnectivity with other dependent social systems might be affected. More people would be involved because of the expansion of residential development, as would other governments, enterprises, and interest groups from geographically distant regions.

These presence-oriented and future-thinking variables offer a more complete picture of the threat pattern and the potential for cascading effects emanating from crisis situations than the unilateral declaration of crisis causes. Hence, the suggestion of possible interactions between a variety of key crisis threat variables exceeds the situational awareness potential of the causal perspective, which often focuses on rigid crisis classifications on the basis of one or a few crisis attributes that are viewed as 'responsible' for the manifestation of the crisis. Moreover, a series of these key crisis threat variables can aggravate situations and processes from relatively normal 
disruptions to severe crises and thereby contribute to highly variable threat patterns and difficult-to predict crises. Consequently, the provision of key crisis threat variables is fundamental for an analytical aid for crisis threat assessment. For example, a crisis threat assessment framework on key crisis threat variables could broaden an assessor's perspective (cf. Table 2) and help him or her to resist the temptation to make a hasty and undifferentiated decision through unilateral processes of situational awareness.

\subsection{Specification of variables}

The identification and consolidation of relevant key crisis threat variables alone is insufficient for the development of analytical aids. The field of crisis management has failed to systematically define and operationalize its fundamental crisis threat variables. Due to the underspecification of its major concepts and variables, analytical results remain largely unverifiable by subsequent studies (Schulman, 2011). As many crisis scholars still consider the uniqueness of a crisis to be a non-alterable concept (Roux-Dufort, 2007), they consequently dispense with the operationalization of variables for cross-case analysis.

This is apparent in the lack of pattern-detecting quantitative cross-case studies currently available in the crisis threat assessment literature that is relevant to public administrations. The large majority of crisis threat treatises ignore quantitative variable testing. The rare quantitative studies in the field do not analyse a series of crises in a comparative manner, but rather cluster crisis threat variables from top manager surveys (e.g., Mitroff et al., 1988; Yin and Jing, 2014). However, the specific variables (e.g., 'limited time' and 'pressure from the public') are not further specified. The very meaning of these variables is left to the reader. Moreover, because organizations rarely have significant experience managing crises (James, Wooten and Dushek, 2011), the corresponding studies may reproduce or rearrange already known insights about threat variables without contributing to greater specification.

One analysis that makes an explicit claim of crosscase pattern detection is the extensive quantitative study of Brecher and Wilkenfeld (2000), which was based on 412 international crises and 895 foreign policy crises. This study created a more critical view of world politics by focussing on hostile and military interactions between adversarial states, but it did not provide sufficient variables and variable specification for the generic approach proposed by this article. Even Gundel's (2005) heuristically-derived but methodologically-sophisticated approach to classification criteria barely meets these requirements. The definition of the two classification criteria 'predictability' (i.e., 'A crisis is predictable, if place, time or in particular the manner of its occurrence are knowable to at least a third competent party and the probability of occurrence is not to be neglected', p. 109) and 'influence' (i.e., 'A disaster or crisis can be influenced if responses to stem the tide or to reduce damages by antagonising the causes of a crisis are known and possible to execute', p. 109) remain at the highly abstract and interpretable level, even though Gundel's approach was developed for theoretical and practical crisis threat assessment. Despite his suggestion that a crisis can be knowable by expert witnesses or through a threshold value established through conventions or precedents, Gundel essentially leaves crisis threat assessors to fend for themselves. Specifications for the terms 'place', 'time', 'manner of occurrence', and 'third competent party' are not provided. The classification criteria 'influence', which represents response possibilities, is even more difficult to apply: The reactive countermeasures should have a sufficient effect, doing more good than harm, and they should exceed simple measures such as evacuation. The impressive methodological content of Gundel's contribution notwithstanding, it is evident that other crisis scholars run into trouble when attempting to critically receive, test, or even build upon such existing treatises. Definitions like Gundel's provide valuable theoretical insights into relevant crisis threat variables, as mentioned in Section 3.1 , but remain inapplicable to a crisis threat assessment framework due to the vague nature of the variables presented.

Hence, crisis threat assessment research must confront this critical issue by considering and testing the specification possibilities for crisis threat variables. In particular, a complex differentiation of these variables that is modelled after the variety of human, social, technical, economic, legal, and ethical crisis dimensions (see Section 2.1), as well as sector-specific circumstances needs to be undertaken. 


\subsection{Consolidation of existing crisis threat assessment treatises}

Given the current state of the literature, it is hardly feasible to create a comprehensive crisis threat assessment framework for public administrations. Indeed it is questionable whether such a general orientation would be requested. For Weick (2007), a diverse set of theories, models, and causal assumptions served as a hedge against surprise and analytical error in crisis situations. However, the consolidation or partial consolidation of existing crisis threat assessment treatises can bring the field closer to complexity-reducing analytical aids. Crisis management is a young field, and all young fields are refined by a certain kind of decoupled experimentation (Dezenhall, 2014); however, the multiplicity of today's crisis threat variables requires an urgent debate about fundamental assumptions in the field. The crisis management literature lacks cumulative research and acknowledged standards that are reflected in methodological approaches. Whereas the concept of crisis has been the subject of profound attention in longestablished disciplines such as history, economics, political science, psychology, medicine, and philosophy, it remains elusive in the field of organizational science and management (Roux-Dufort and Lalonde, 2013). In other academic fields, standardization attempts have been intensively implemented: Doctors profit from standard examination methods and general models detecting diseases, psychotherapists can choose between a host of methodological schools (such as psychoanalysis, behavioural psychology, and client-centred psychotherapy) in response to individual crises, and economists have defined a range of standard factors that can influence financial crises (such as the investment of currency reserves, changes in interest rates, price stability, and consumer behaviour). Even the crisis management-related field of risk management provides an integral risk assessment framework involving a series of risk categories and a risk matrix with the axes 'probability' and 'extent of damage'. Thanks to the introduction of this framework, risk assessment has become a part of a rational decision-making process that allows the description and comparison of the costs and utilities of potential risk-mitigating options (Habegger, 2010).
The crisis management literature is a long way away from such a methodological and conceptual consensus. In order to mature as a scientific field and consolidate its previous findings, the field must present existing insights in such a way that they are easily accessible, which in turn would facilitate dialectical processes between crisis management scholars. This is the cornerstone of an academic field: systematizing its findings and establishing central concepts, categories, and measurement definitions (Klaus and Buhr, 1975). Crisis management scholars must therefore properly define and operationalize their concepts in a universal or methodology-specific manner in order to make their concepts interesting for cumulative research, thereby promoting the development of crisis threat assessment theory. The assumption that every crisis is different and not understandable with tools and frameworks (Topper and Lagadec, 2013) must be critically challenged, as this is essentially the same as saying that doctors do not need standard examination methods because every patient is unique and will exhibit an individual disease pattern to which he or she will respond in a unique way.

No analytical method or framework for crisis threat assessment should be declared sacrosanct or exclusively applicable for pattern detection, but if theoretical constructs are included in our deliberations, the field could prevent the loss of sophisticated data and analytical approaches in the current scattered (Roux-Dufort, 2007) and incoherent conceptual morass.

\section{Conclusion, Limitations and Future Research}

This study sought to overcome a shortcoming in the research by consolidating previous literature that is relevant to crisis threat assessment by public administrations. In addition, and in answer to the first research question, Section three showed that fragmentary, unspecific, and unconsolidated theoretical treatises have little sustainable effect on the specific research. In particular, the field is struggling to develop an effective body of analytical aids that are relevant to public administrations.

This represents a profound lacuna in the crisis management literature, as the increasing variety of influencing variables in today's world can easily overstrain a crisis threat assessor's capabilities. As Vertzberger (1990) noted a quarter-century ago, when the 
flood of information was not nearly as overwhelming as it is today, it is not the lack of information but the misperception of available information that regularly leads to inappropriate decisions. Crisis management scholars can minimize such aberrations if they systematically define the key variables and fields of crisis threat assessment by analysing the influence of variables in terms of cross-case relevance. If we continue to argue that everything that occurs in crisis situations is dependent on the specific circumstances, then the field of crisis management risks losing its legitimacy as an academic field by ignoring scientific premises, as discussed above in Section three. It must therefore establish its central concepts by constructing fieldappropriate analytical aids around key crisis threat variables. Moreover, analytical frameworks must be refined for public administration departments/subsections with assigned variables for federal administrations, lower levels of government (Ladner and Soguel, 2015), different policy sectors, and industry-specific conditions. Table 2 presents an example of how the field "public administration" could be outlined with regards to the literature examined in this article (cf. Section 2).

This variable overview, which is based on the literature reviewed in Section two, may be adequate to answer the second research question. Each variable's influence must be specified, operationalized, and tested through confirmative analysis in future research. The advantage of the variable list is that it provides a more exhaustive view of relevant key crisis threat variables than previous approaches. For example, eleven variables that address assertiveness and the quality of information support the determination of potential "influences" (Gundel, 2005) on a crisis.

However, the framework presented here is insufficient for establishing an analytical aid, since it leaves the identification of causal linkages and the solution of the analytical puzzle to the crisis threat assessor. Restricting the crisis threat assessment framework to public administrations - and the very field of crisis threat assessment itself - therefore only meet the analytical requirements when the influence of a variable or a variable combination is linked with a certain degree of validity or statistical significance. To this end, challenging and well-specified explanatory hypotheses on the linkages between key crisis threat variables or between key crisis threat variables and a certain outcome must be formulated and tested through exploratory and confirmatory cross-case analysis.

Because the under-specified concepts in the crisis management literature are unlikely to lead to powerful and testable hypotheses (Schulman, 2011), we can scarcely verify or disprove the existing research. The scientific challenge for the field of crisis threat assessment is thus to move towards a fundamental theorization through the systematic cross-case study of key crisis threat variables in a variety of subfields. Because this requires, among other things, the use of unfamiliar approaches, renewing the debate on adequate methods for crisis threat assessment is a promising future direction.

Table 2. Potential crisis threat assessment framework for public administrations

\begin{tabular}{|c|c|c|c|}
\hline Crisis threats & Information quality & $\begin{array}{l}\text { Political-administrative } \\
\text { challenges }\end{array}$ & $\begin{array}{l}\text { Assertiveness of the crisis } \\
\text { management team }\end{array}$ \\
\hline $\begin{array}{l}\text { - Novelty } \\
\text { - Latency } \\
\text { - Crisis development } \\
\text { - Spatial impact of the crisis } \\
\text { - Extent of damage } \\
\text { - Reversibility } \\
\text { - Mobilization potential }\end{array}$ & $\begin{array}{l}\text { - Access to information } \\
\text { - Consensus on utility of } \\
\text { information } \\
\text { - Consensus on crisis } \\
\text { severity } \\
\text { - Knowledge of causes } \\
\text { - Uncertainty level of } \\
\text { potential solutions }\end{array}$ & $\begin{array}{l}\text { - Vertical political } \\
\text { boundaries } \\
\text { - Horizontal political } \\
\text { boundaries } \\
\text { - Policy areas } \\
\text { - Time demarcation }\end{array}$ & $\begin{array}{l}\text { - Responsibility } \\
\text { - Degree of interference with } \\
\text { normal operations } \\
\text { - Consensus on (political) } \\
\text { goals } \\
\text { - Concurrent stressors } \\
\text { - Autonomy } \\
\text { - Availability of resources }\end{array}$ \\
\hline
\end{tabular}




\section{References}

Ansell, C., Boin, A. and Keller, A., Managing Transboundary Crises: Identifying the Building Blocks of an Effective Response System, Journal of Contingencies and Crisis Management 18(4)(2010), 195-207.

Antonacopoulou, E.P. and Sheaffer, Z., Learning in Crisis: Rethinking the Relationship Between Organizational Learning and Crisis Management, Journal of Management Inquiry 23(1)(2013), 5-21.

Bayne, J., An Overview of Threat and Risk Assessment (SANS Institute, Swansea UK, 2002).

Beck, U., Weltrisikogesellschaft: Auf der Suche nach der verlorenen Sicherheit 1st ed. (Suhrkamp Verlag, Frankfurt am Main, 2007).

Boin, A., From Crisis To Disaster: Towards An Integrative Perspective, in What is a disaster?: New answers to old questions, eds. Perry R. W. and Quarantelli E. L. (Xlibris Corporation, 2005) pp. 153-172.

Boin, A. and 't Hart, P., Public Leadership in Times of Crisis: Mission Impossible?, Public Administration Review 63(5)(2003), 544-553.

Boin, A. and Lagadec, P., Preparing for the Future: Critical Challenges in Crisis Management, Journal of Contingencies and Crisis Management 8(4)(2000), 185191.

Boin, A. and McConnell, A., Preparing for Critical Infrastructure Breakdowns: The Limits of Crisis Management and the Need for Resilience, Journal of Contingencies and Crisis Management 15(1)(2007), 50-59.

Brecher, M. and Wilkenfeld, J., A Study of Crisis (University of Michigan Press, Ann Arbor, 2000).

Brown, K.A. and Ki, E.-J., Developing a Valid and Reliable Measure of Organizational Crisis Responsibility, Journalism \& Mass Communication Quarterly 90(2)(2013), 363-384.

Canon-Bowers, J.A. and Bell, H.H., Training Decision Makers for Complex Environments: Implications of the Naturalistic Decision Making Perspective, in Naturalistic decision making, eds. Zsambok C. E. and Klein G. A. (L. Erlbaum Associates, Mahwah, N.J., 1997) pp. 99-110.

Claeys, A.-S. and Cauberghe, V., Keeping Control: The Importance of Nonverbal Expressions of Power by Organizational Spokespersons in Times of Crisis, Journal of Communication 64(6)(2014), 1160-1180.

Coombs, W.T., Protecting Organization Reputations During a Crisis: The Development and Application of Situational Crisis Communication Theory, Corporate Reputation Review 10(3)(2007), 163-176.

Crichton, M.T., Lauche, K. and Flin, R., Incident command skills in the management of an oil industry drilling incident: A case study, Journal of Contingencies and Crisis Management 13(3)(2005), 116-128.

Dayton, B.W., Managing Crises in the Twenty-First Century, International Studies Review 6(1)(2004), 165-194.

Dezenhall, E., Glass Jaw: A Manifesto for Defending Fragile Reputations in an Age of Instant Scandal (Twelve, New York, NY, 2014).
Doktor, C., Krisenmanagement im Wandel: Grundlagen, konzeptionelle Weiterentwicklung und aktuelle Trends, in Bulletin 2007 zur schweizerischen Sicherheitspolitik, eds. Wenger A. and Mauer V. (Center for Security Studies (ETH Zürich), Zürich, 2007) pp. 11-39.

Enander, A., Lajksjö, Ö. and Tedfeldt, E.-L., A tear in the social fabric: Communities dealing with socially generated crises, Journal of Contingencies and Crisis Management 18(1)(2010), 39-48.

Endsley, M.R. and Garland, D.J. eds., Situation Awareness Analysis and Measurement (CRC Press, Mahwah, NJ, 2000).

Fink, S., Crisis Management: Planning for the Inevitable Rev. (iUniverse, Lincoln, Neb, 2000).

Gephart, R.P., Van Maanen, J. and Oberlechner, T., Organizations and Risk in Late Modernity, Organization Studies 30(2-3)(2009), 141-155.

German Advisory Council on Global Change, Strategies for Managing Global Environmental Risks: Annual Report 1998 (Springer, Berlin, Heidelberg, 1998).

Gundel, S., Towards a New Typology of Crises, Journal of Contingencies and Crisis Management 13(3)(2005), 106115.

Habegger, B., Bewertung von Risiken (Center for Security Studies (ETH Zürich), Zürich, 2010).

Hart, C., Doing a Literature Review: Releasing the Social Science Research Imagination (SAGE Publications, London, 1998).

't Hart, P. and Boin, A., Between crisis and normalcy: The long shadow of post-crisis politics, in Managing crises: threats, dilemmas, opportunities, eds. Rosenthal U.,Boin A., and Comfort L. K. (Charles C Thomas, Springfield, IL, 2001) pp. 28-46.

't Hart, P., Heyse, L. and Boin, A., New Trends in Crisis Management Practice and Crisis Management Research: Setting the Agenda, Journal of Contingencies and Crisis Management 9(4)(2001), 181-188.

Hohl, M., Brem, S. and Balmer, J., A Method for Risk Analysis of Disasters and Emergencies in Switzerland (Swiss Federal Office for Civil Protection, Bern, 2013).

Howitt, A.M. and Leonard, H.B., The Novelty of Crises: How To Prepare For the Unprecedented, in The L.A. Earthquake Sourcebook, eds. Lewis J. and Ulin D. (Designmatters at Art Center College of Design, Pasadena, CA, 1 February 2009) pp. 210-217.

Hwang, P. and Lichtenthal, J.D., Anatomy of organizational crises, Journal of Contingencies and Crisis Management 8(3)(2000), 129-140.

International Risk Governance Council, An Introduction to the IRGC Risk Governance Framework (International Risk Governance Council, Geneva, 2008).

James, E.H., Wooten, L.P. and Dushek, K., Crisis Management: Informing a New Leadership Research Agenda, The Academy of Management Annals 5(1)(2011), 455-493. 
Jaques, J.-M., Gatot, L. and Wallemacq, A., A cognitive approach to crisis management in organizations, in International handbook of organizational crisis management, eds. Pearson C. M.,Roux-Dufort C., and Clair J. (Sage Publications, Los Angeles, 2007) pp. 161-192.

Klaus, G. and Buhr, M., Philosophisches Wörterbuch (Bibliographisches Institut, Leipzig, 1975).

Klinke, A. and Renn, O., Precautionary principle and discursive strategies: classifying and managing risks, Journal of Risk Research 4(2)(2001), 159-173.

Kouzmin, A., Crisis Management in Crisis?, Administrative Theory \& Praxis 30(2)(2008), 155-183.

Ladner, A. and Soguel, N., Managing the crises - how did local governments react to the financial crisis in 2008 and what explains the differences? The case of Swiss municipalities, International Review of Administrative Sciences 81(4)(2015), 752-772.

Lalonde, C., The Potential Contribution of the Field of Organizational Development to Crisis Management, Journal of Contingencies and Crisis Management 15(2)(2007), 95-104.

Lalonde, C., Managing crises through organisational development: a conceptual framework, Disasters 35(2)(2011), 443-464.

La Porte, T.R., Anticipating Rude Surprises, in Communicable Crises: Prevention, Response, and Recovery in the Global Arena, ed. Gibbons D. E. (IAP, Charlotte, NC, 2007) pp. $27-44$.

Lewis, G.W., Organizational crisis management: the human factor (Auerbach Publications, Boca Raton, 2006).

McAuley, E., Duncan, T.E. and Russell, D.W., Measuring Causal Attributions: The Revised Causal Dimension Scale (CDSII), Personality and Social Psychology Bulletin 18(5)(1992), 566-573.

Mitroff, I.I., Crisis Management: Cutting Through the Confusion, Sloan Management Review 29(2)(1988), 15-20.

Mitroff, I.I. and Alpaslan, M.C., Preparing for evil, Harvard Business Review 81(4)(2003), 109-115.

Mitroff, I.I., Pauchant, T.C. and Shrivastava, P., The structure of man-made organizational crises: Conceptual and empirical issues in the development of a general theory of crisis management, Technological Forecasting and Social Change 33(2)(1988), 83-107.

Pasquier, M. and Fivat, E., Crisis Communication Characteristics \& Errors: A Case Study, Public Communication Review 2(1)(2012), 16-34.

Quarantelli, E.L., Another Selective Look at Future Social Crises: Some Aspects of Which We Can Already See in the Present, Journal of Contingencies and Crisis Management 9(4)(2001), 233-237.

Robert, B. and Lajtha, C., A New Approach to Crisis Management, Journal of Contingencies and Crisis Management 10(4)(2002), 181-191.

Rosenthal, U., Boin, A. and Comfort, L.K. eds., Managing crises: threats, dilemmas, opportunities (C. C. Thomas, Springfield, 2001).
Rosenthal, U., Charles, M.T. and 't Hart, P., Coping with crises: the management of disasters, riots, and terrorism (C.C. Thomas, Springfield, IL, 1989).

Rosenthal, U. and Kouzmin, A., Globalizing an Agenda for Contingencies and Crisis Management: An Editorial Statement, Journal of Contingencies and Crisis Management 1(1)(1993), 1-12.

Roux-Dufort, C., Is crisis management (only) a management of exceptions?, Journal of contingencies and crisis management 15(2)(2007), 105-114.

Roux-Dufort, C. and Lalonde, C., Editorial: Exploring the Theoretical Foundations of Crisis Management, Journal of Contingencies and Crisis Management 21(1)(2013), 1-3.

Schulman, P.R., Problems in the Organization of Organization Theory: An Essay in Honour of Todd LaPorte, Journal of Contingencies and Crisis Management 19(1)(2011), 4350.

Shapiro, D.E. and Koocher, G.P., Goals and practical considerations in outpatient medical crises intervention, Professional Psychology: Research and Practice 27(2)(1996), 109-120.

Sheaffer, Z., Richardson, B. and Rosenblatt, Z., EarlyWarning-Signals Management: A Lesson from the Barings Crisis, Journal of Contingencies and Crisis Management 6(1)(1998), 1-22.

Sikich, G.W., Emergency Management Planning Handbook (McGraw-Hill Inc.,US, New York, 1995).

Stern, E.K., Crisis Navigation: Lessons from History for the Crisis Manager in Chief, Governance 22(2)(2009), 189 202.

Svedin, L.M., Organizational Cooperation in Crises (Ashgate Publishing Limited, Farnham, England, 2009).

Swiss Re, Sigma: Natural catastrophes and man-made disasters in 2014 (Swiss Re (Sigma), Zurich, 2015).

Töpfer, A., Plötzliche Unternehmenskrisen - Gefahr oder Chance?: Grundlagen des Krisenmanagement, Praxisfälle, Grundsätze zur Krisenvorsorge (Hermann Luchterhand Verlag, Neuwied; Kriftel, 1999).

Topper, B. and Lagadec, P., Fractal Crises - A New Path for Crisis Theory and Management, Journal of Contingencies and Crisis Management 21(1)(2013), 4-16.

Vertzberger, Y.Y.I., The World in Their Minds: Information Processing, Cognition, and Perception in Foreign Policy Decisionmaking (Stanford University Press, Stanford, 1990).

Weick, K.E., The collapse of sensemaking in organizations: The Mann Gulch disaster, Administrative Science Quarterly 38(4)(1993), 628-652.

Weick, K.E., The Generative Properties of Richness, Academy of Management Journal 50(1)(2007), 14-19.

Yin, S.and Jing, R., A Schematic View of Crisis Threat Assessment, Journal of Contingencies and Crisis Management 22(2)(2014), 97-107. 